\title{
Linear discontinuous deformations in the light of investigations performed with ERT method
}

\author{
Piotr Strzałkowski, Roman Ścigała, Katarzyna Szafulera*, Marek Kruczkowski \\ Silesian University of Technology, Faculty of Mining and Geology, Gliwice, Poland
}

\begin{abstract}
The article presents an example of using the electrical resistivity tomography method to assess the condition of shallow rock mass layers in the area of linear discontinuous deformations created in the past due to underground mining activity. The research concerned the mining area of one of the Upper Silesian Coal Basin mines, where intensive mining operations have been conducted for several decades. In the considered area, linear discontinuous deformations were created in the form of ground steps. Their location is related to characteristic layout of deposit accessing roadways and extraction fronts in several coal seams. The article analyzes the geological structure of the deposit and the state of deformation of the rock mass caused by mining operations. In order to evaluate the hitherto impacts, appropriate calculations of the extraction influence were performed, assuming different views on the summation of horizontal strain in long time intervals. The calculations were carried out using the theory of W.Budryk - S. Knothe. Theoretical considerations were supplemented with geophysical surveys performed with using electrical resistivity tomography. Obtained results of the near-surface layers ERT imaging in the form of resistivity profiles confirm the existence of rock loosening zones in the areas of discontinuous deformations occurrence.
\end{abstract}

Keywords: post-mining discontinuous deformations, linear deformations, ERT method

\section{Introduction}

Underground mining extraction causes two types of surface deformations : continuous where no visible breaks in near surface layers is visible and discontinuous - where discontinuity on the surface is observed and some relative movement on both sides of discontinuity occurred in vertical and/or horizontal direction. Continuous deformations manifest on the surface in the shape of so-called subsidence troughs. They always accompany underground mining - with deeper extraction they tend to be more smooth but occupy wider area on the surface $[2,7,10]$. A number of prediction models in this field was developed in Poland, e.g. $[6,8,12]$.

\footnotetext{
*Corresponding autor: katarzyna.szafulera@polsl.pl
} 
Discontinuous deformations, according to their shape, may be divided into two types : surface-type and linear-type. They not always take place - some favorable additional factors must exist to trigger them [3, 4, 10, 14].

Typical example of surface-type discontinuous deformation is a sinkhole [3]. Presently, in Upper Silesian Basin they are not as common as it was in the past, because of greater depth of extraction nowadays and connected with it different mechanism of their creation. It is usually tied with instability of old shallow workings caused by influences of presently performed deep extraction.

Linear discontinuous deformations are significant problem arising on the surface as the effect of underground mining operations. The main causes for their formation include:

- mining extraction in the vicinity of tectonic faults (in particular on one side of dislocation)

- asymmetric extraction of several deposit layers to given (same) border line - usually the limit of different pillars (protective, safety etc.) - see Fig. 2.

Linear deformations commonly arise on the land surface in the shape of ground steps (Fig. 1), trenches, cracks and fissures. Characteristic is, that they usually spread along one direction, sometimes for several hundreds of meters, while perpendicular dimensions stay relatively small. Very often, parallel system of such deformations is created - in Fig. 1 two ground steps are visible, crossing the road.

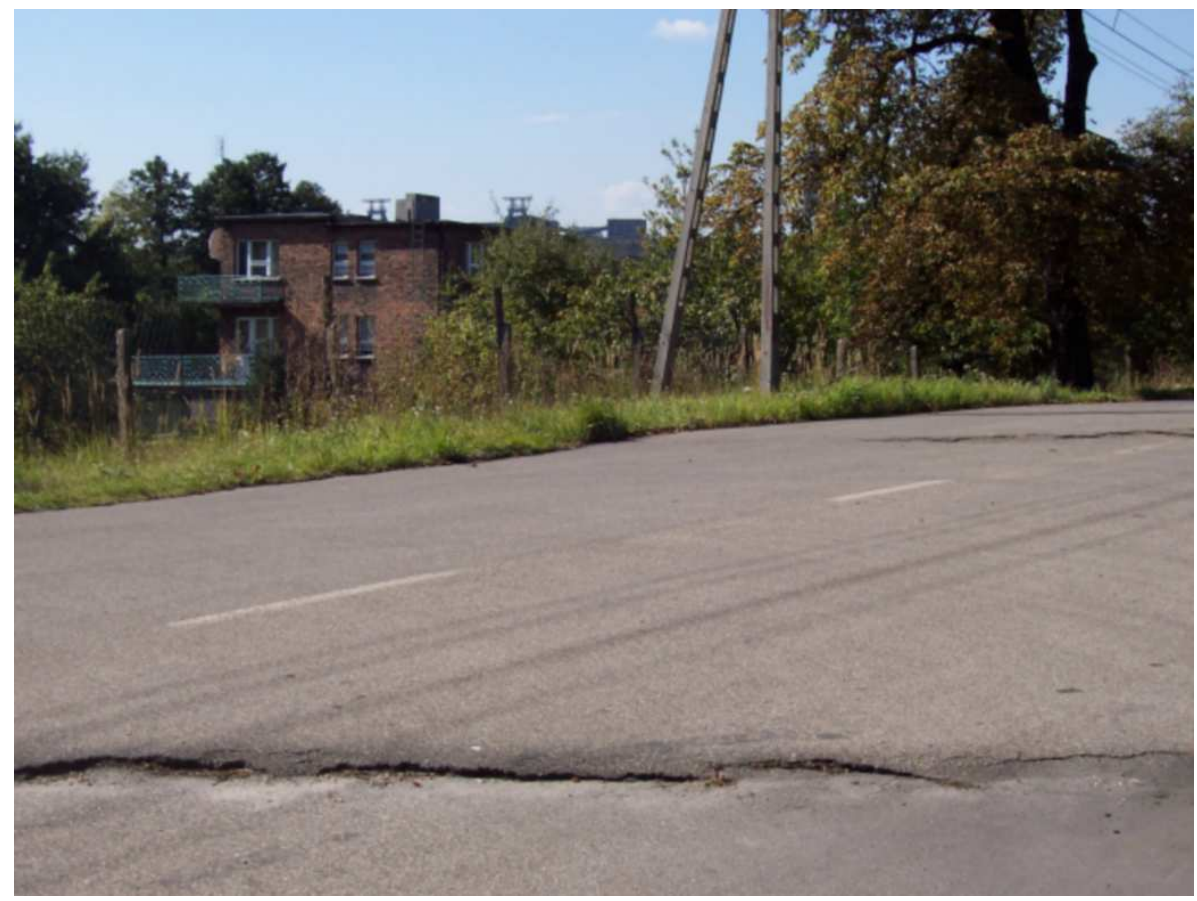

Fig. 1. Typical ground step created as the effect of mining of several coal seams to the border of protective pillar (photo by R. Ścigała).

The results of some research show, that significant influence on the formation of linear discontinuous deformations have also high values of horizontal tensile strain, which may occur in case of very intensive one-sided extraction or mutual influence of extraction edges located at the distance not greater than the influence range - Fig. 3. In such case, horizontal strain resulting from every extraction edge is going to be summed, which finally may double its value. According to [9], the critical value of horizontal strain necessary to trigger ground 
steps amounts approximately 12-15\%, while the activation of already existing (created earlier) deformations may occur with strain greater than $2 \%$.

Regardless of the cause of deformation, they pose a serious threat to the surface. In order to be able to recognize such threat, it is necessary to conduct detailed analysis of geological and mining conditions, as well as to assess the condition of shallow rock mass layers in the considered location.

One of the methods of determining the anomaly zones in the geological structure of the near-surface layers of the rock mass in a non-destructive way is the use of geophysical methods.

In the framework of this paper, practical example has been shown of ERT investigation in the area of linear discontinuous deformations triggered due to mining activity. The aim of the study was to confirm the usability of ERT imaging for recognition of the threat of discontinuous deformation arising in the areas of intensive underground mining operations.

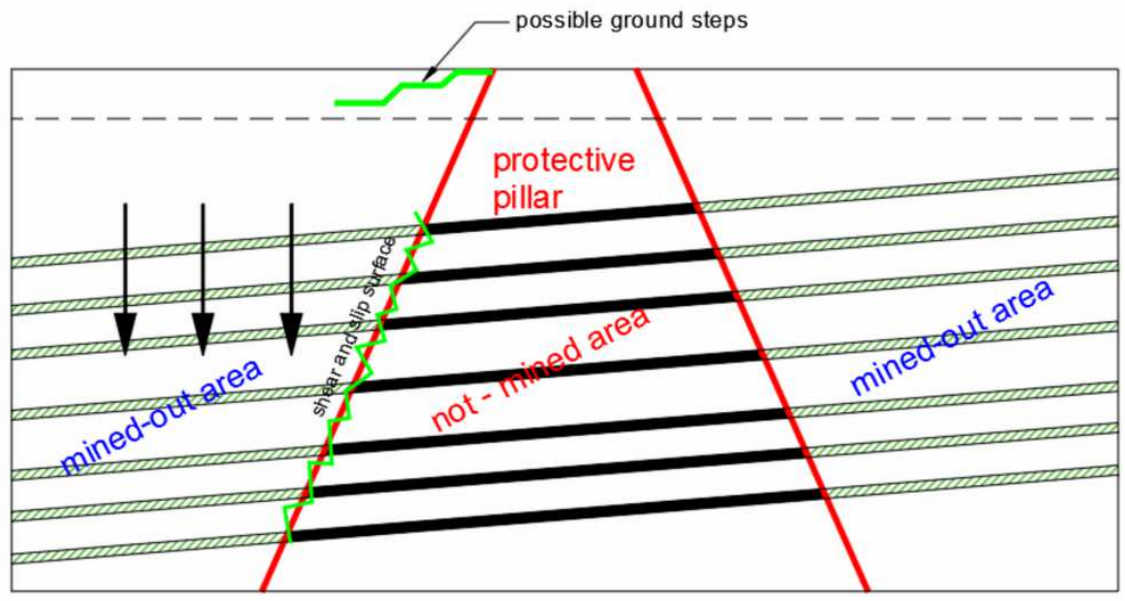

Fig. 2. Extraction scarps in the border area of protective pillar as the cause of ground steps creation.

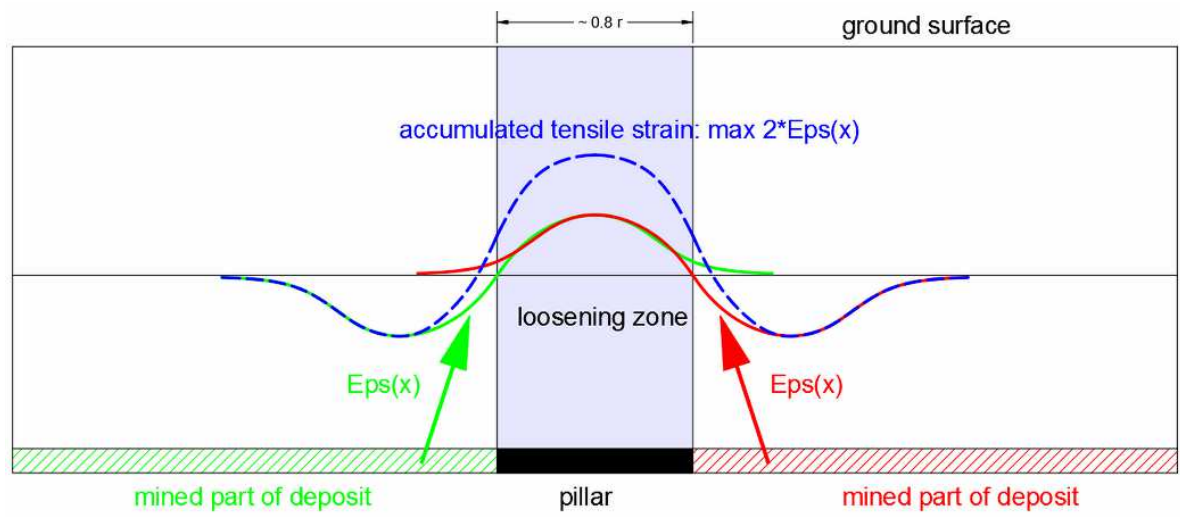

Fig. 3. Mining conditions of horizontal strain (Eps) accumulation on the surface.

\section{Mining and geological conditions in the investigation area}

\section{The description of discontinuous deformations}

As the effect of long term underground mining to the same border of safety pillar, system of ground steps was created on the surface, crossing grassland - Fig. 4-6. The throw of every 
step amounts from $0.5 \mathrm{~m}$ to $1.0 \mathrm{~m}$. Because they arose in arable area, the discontinuity was not clearly visible - steps formed a kind of fissure. The length of deformation exceeded $200 \mathrm{~m}$, while in perpendicular direction the average distance between every step was about $50 \mathrm{~m}$.

\section{Geological conditions}

In the area of interest, rock mass is built of the following layers: Quaternary, Tertiary, Triassic and Carbon.

- Quaternary layers cover the whole considered area. They are built mainly of sand, gravel and loam. Maximum thickness of Quaternary layers reaches $32 \mathrm{~m}$.

- Tertiary part of the rock mass of thickness about $248 \mathrm{~m}$ consists of loam with limestone inserts and blue-gray shale with gypsum.

- Triassic layers with thickness of 40m are built mainly of shell limestone.

- Carbon up to the depth 900m consists of "orzeskie" and "rudzkie" layers. They are formed mainly by claystones, mudstones, hard coal layers and coal shales.

- In the considered area, there is lack of important tectonic faults.

\section{Underground mining extraction conducted in the area of interest}

"Orzeskie" layers were extracted in the period 1985 - 1997, with thickness from $1.3 \mathrm{~m}$ to 3.5 $\mathrm{m}$, at the depth from $380 \mathrm{~m}$ to $580 \mathrm{~m}$. Extraction was led by using longwall system with caving.

Coal seams from "rudzkie" layers were extracted from the year 1962 up to 2002, with thickness from $1.3 \mathrm{~m}$ to $3.4 \mathrm{~m}$, at the depth from $380 \mathrm{~m}$ to $820 \mathrm{~m}$. Extraction was led by using longwall system with caving.

In Fig. 4 the map of total thickness of extracted deposit is shown - different colors mark different intensity of extraction. White area marks unextracted part - the protective pillar, designed for protection of main deposit accessing roadways.

As it can be seen from this picture, there is high diversity of extracted deposit - from $0 \mathrm{~m}$ at the pillar location up to $20 \mathrm{~m}$ towards south and $15 \mathrm{~m}$ towards north. Such situation created conditions for ground steps creation - on both sides of the pillar a large amount of deposit has been extracted, which favors the possibility of rock mass vertical shear-slip along the plane of multiple extraction edges. Additionally, above the pillar high tensile horizontal strain occurred, which undoubtedly was an additional factor favorable for rock mass vertical slip.

\section{Performed calculations}

For calculation of maximum strain, which probably took place above the protective pillar, Budryk - Knothe theory [6] was used, implemented into dedicated software [15]. Because of long history of extraction in this area, different strain summation methods were used :

- simple summation which usually leads to exaggerated (abnormally high) strain values in case of considering long time periods,

- $\quad$ summation in 10-years independent extraction periods [7],

- $\quad$ summation with the assumption of strain relaxation $[1,11]$.

For calculation purposes, the following parameters of Budryk-Knothe theory where taken : coefficient of roof control $\mathrm{a}=0.84$, parameter describing the influence dispersion $\operatorname{tg} \beta=2.2$, parameter responsible for description of horizontal component of deformations: $\mathrm{B}=0.32 \mathrm{r}$ (where $\mathrm{r}$ is the radius of main influence range). Parameters were determined on the basis of surveys led in this area in the past.

Computer aided simulation of extraction was then performed in order to assess possible maximum values of strain during different positions of extraction front. Obtained maximum values of tensile horizontal strain are presented in table 1.

As it comes from performed calculations, the value of strain greater than 12 [\%o] took place in the end of 70s of the last century. Unfortunately no information is available about ground steps creation in those years. First their findings come from the year 2002, where they 
probably were activated by extraction led at that moment, with smaller strain values - at the level of $2[\%]$.

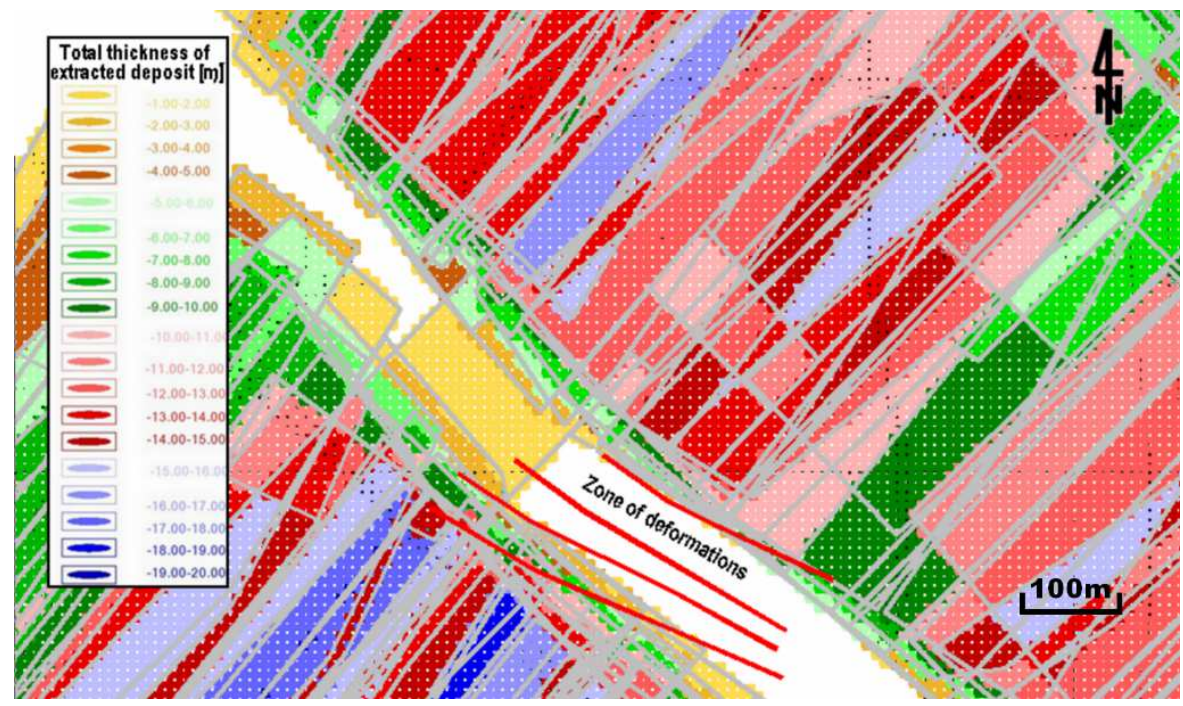

Fig. 4. The map of total thickness of extracted deposit in the vicinity of created linear discontinuous deformations.

Table 1. Total horizontal strain $\varepsilon$ max calculated over long time periods with different summation methods

\begin{tabular}{|l|c|}
\hline \multicolumn{1}{|c|}{ Horizontal strain summation method } & $\begin{array}{c}\text { Maximum } \\
\text { strain value }\end{array}$ \\
\hline 1. Simple summation of horizontal strain & $+\mathbf{2 8 . 9}[\%$ ] \\
\hline 2. Horizontal strain calculated over 10-years extraction periods & $+\mathbf{1 2 . 9}[\%$ ] \\
\hline 3. With using the assumption of relaxation of horizontal strain & $+\mathbf{1 3 . 6}[\% \%]$ \\
\hline
\end{tabular}

\section{ERT methodology, results and its discussion}

\subsection{ERT methodology}

In September 2017, a study was carried out to assess the structure of surface rock mass layers using the ERT method. The terrain morphology was not complicated, surface is generally horizontal - planar, with average height of $250 \mathrm{~m}$ above sea level. Most of the study area is occupied by arable fields and grassland (Fig. 5). For measurements, the GF-Instruments Ares II unit was used [5]. The profile was located transversely in relation to the course of 4 linear discontinuous deformations (Fig. 6). The discontinuous deformation zones crosses the ERT profile at the positions of electrodes: No 15 - 17, No 27 - 29 and 40 - 42.

The ERT profile line consisted of 48 electrodes arranged along a straight line stretched from NE (electrode No. 1) towards SW (electrode No. 48), at the intervals of $4 \mathrm{~m}$. The total length of the profile was $188 \mathrm{~m}$, hence the maximum penetration depth, which may be estimated at about $1 / 5$ of the maximum spacing of electrodes [13] was about $38 \mathrm{~m}$. 


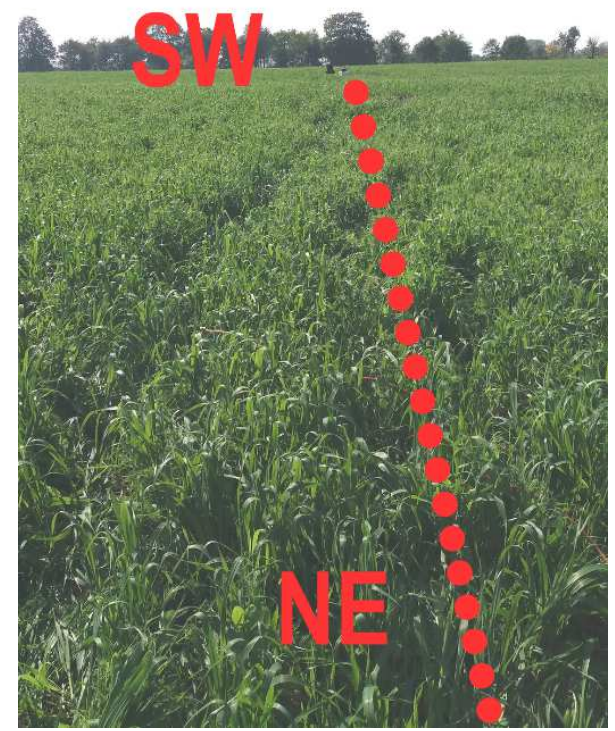

Fig. 5. General view of survey site.

ERT survey was performed with using three arrays: "Wenner $\alpha$ " (360 measurements), "Wenner-Schlumberger" (529 measurements), "Dipol - Dipol HD" (1288 measurements). The measurement results were processed using the Res2DInv software [13]. Fig. 7 presents the obtained ERT profiles in the form of maps of resistance distribution obtained with classical inversion procedure implemented in Res2DInv.

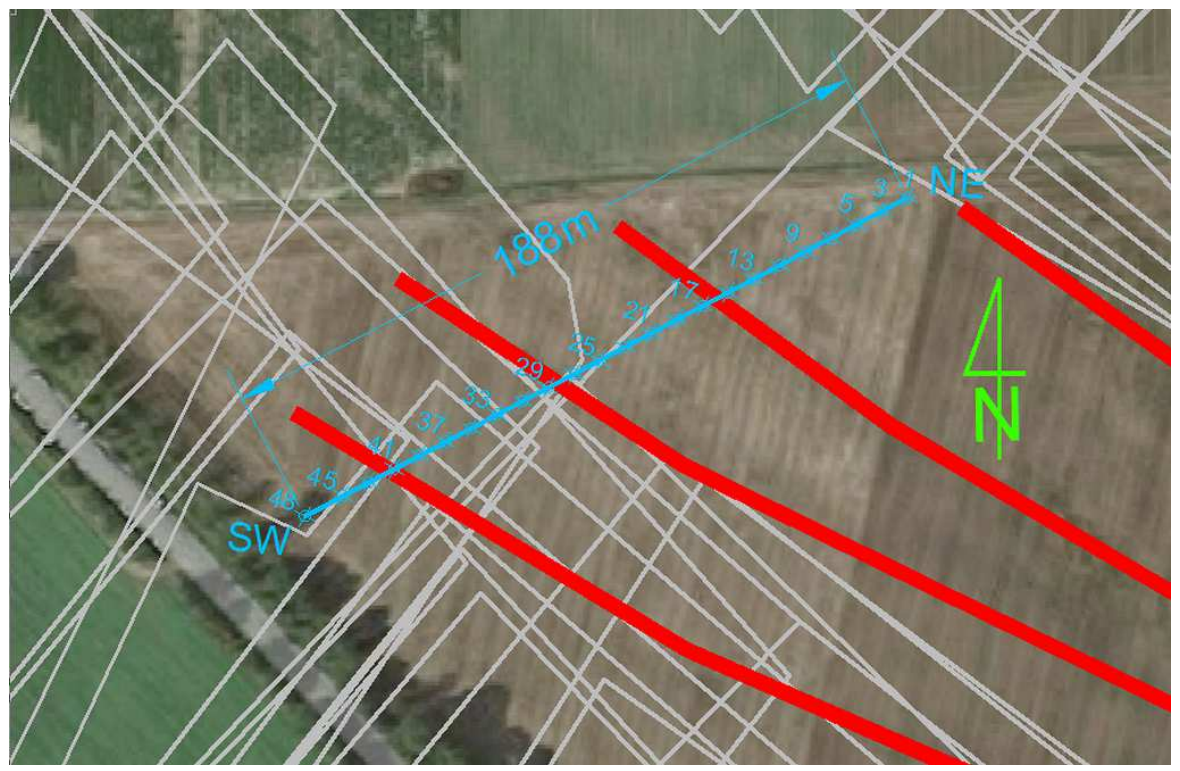

Fig. 6. Location of ERT profile (blue) on the background extracted fields edges (gray) and the course of linear deformations (red). 


\subsection{Results and its discussion}

In Fig. 7, on the background of resistivity distribution, location of ground steps is shown, marked with black rectangle. Analyzing this image, it can be seen, that in the area of ground steps, the zone of higher resistivity is visible in subsurface layers. So it may be stated, that there is evident change in rock mass structure, especially its loosening due to high values of tensile horizontal strain. The second important factor influencing the anomalies visible in ERT image is a shear-slip of fractured rocks in the vicinity of system of extraction edges, which finally revealed on the surface in the shape of linear discontinuous deformations.

It should also be mentioned, that all used arrays gave similar image of resistivity changes, although Dipole-Dipole HD presents more detailed distribution of resistivity near discontinuity zones.

Of course presented interpretation of ERT investigation must be treated with some attention - another recognition methods should be used (geophysical or mining) to confirm in-situ deformation state in near-surface layers.
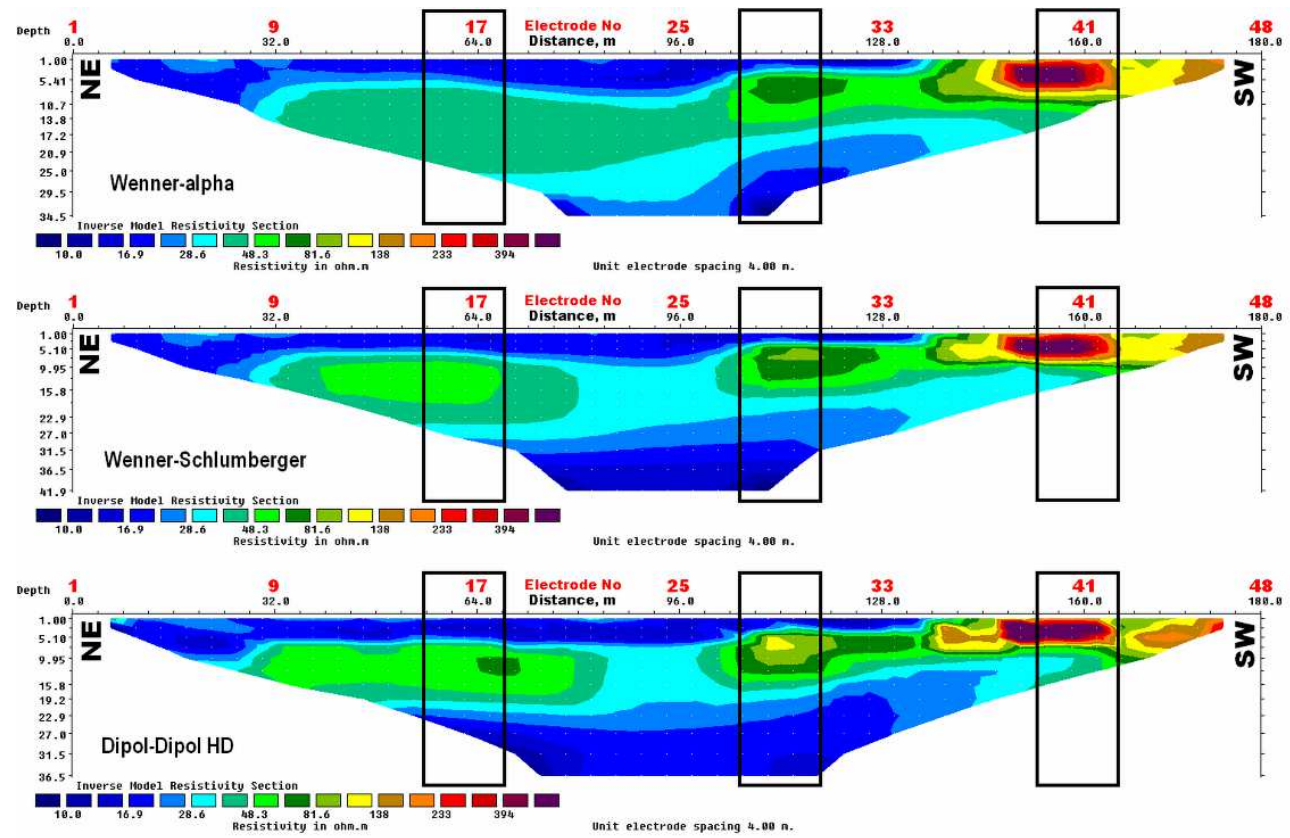

Fig. 7. The ERT cross-sections $[\Omega \mathrm{m}]$ obtained with three survey arrays: Wenner alpha (top), WennerSchlumberger (middle) and Dipol-Dipol HD (bottom).

\section{Conclusions}

Study presented in this work allow to make the following final statements and remarks:

1. The area under investigations is located in the zone of past, very intensive extraction led in several coal seams to the same border defined by protective pillar designed for protection of important underground roadways.

2. On the surface, several ground steps occurred with direction strictly related to the system of finished extraction edges, outside extracted area. Due to this fact, additional adverse element occurred - high values of tensile horizontal strain, which undoubtedly was an element favourable for rock mass loosening. 
3. Presented ERT images show existence of several high resistivity anomalies in the areas, where discontinuous deformation were created on the land surface. So it may be stated, that there is the evident change in rock mass structure (loosening) due to high values of tensile horizontal strain and shear-slip of fractured rocks in the vicinity of extraction edges.

4. Due to the fact, that there was no possibility of practical confirmation of mentioned above findings - for example by drilling, presented interpretation must be treated with care. It is necessary to remember, that quality of ERT surveys depends on many factors, which cannot always all be taken into account.

5. ERT surveys performed in the area of intensive underground extraction conducted in the past, may help in finding zones of rock mass loosening, which in turn may enable more precise determination of areas exposed to the threat of linear-type discontinuous deformation creation.

\section{References}

1. J. Białek, The description of transient phase of mining area subsidence with taking into account the asymmetry of final influences, Research Journal of Silesian University of Technology, Mining series 194, Gliwice (1991) (in Polish)

2. M. Chudek, Geomechanics and basics of management of environmental protection in mining and post-mining areas, Publishing House of the Silesian University of Technology, Gliwice (2010) (in Polish)

3. M. Chudek, W. Janusz, J. Zych, A study concerning recognition of creation and prediction of discontinuous deformations due to underground extraction of deposits. Research Journal of Silesian University of Technology, Mining series 141, Gliwice (1988) (in Polish)

4. Z. Fajklewicz, W. Piwowarski, J. Radomiński, E. Stewarski, A. Tajduś, The investigation of rock mass deformation state aiming at recovering the post-mining land development capability, Publishing House of the AGH University of Science and Technology, Kraków (2004) (in Polish)

5. GF-Instruments, ARES II, Automatic resistivity \& IP system, User guide, Czech Republic, Brno (2014)

6. S. Knothe, The equation of finally formed profile of subsidence trough, Archive of Mining and Metallurgy 1, 1 (1953) (in Polish)

7. S. Knothe, Forecasting the impact of mining exploitation, „Śląsk” Publishing House. Katowice (1984) (in Polish)

8. T. Kochmański, Integral Theorie der Bodenbergungen unter Einnirkung des Abbaus, Freiberger Forschungshefte, A.1/18, Freiberg (1959) (in German)

9. A. Kowalski, Recognition and possibilities of prediction of linear discontinuous deformations, Proceedings of the Conference: $8^{\text {th }}$ Days of Mining Surveys and Protection of Mining Areas, Ustroń, Poland (2005) (in Polish)

10. H. Kratzsch, Mining Subsidence Engineering, Springer-Verlag, Berlin, Heidelberg, New York (1983)

11. J. Kwiatek, On rheological aspects of the threat of building constructions located in mining areas, Scientific Works of Central Mining Institute 827, Katowice (1997) (in Polish)

12. J. Litwiniszyn, Differential equation of rock mass displacement, Archive of Mining and Metallurgy 1, 1 (1953) (in Polish)

13. M. H. Loke, $2 D \& 3 D$ electrical imaging surveys, Geotomo software: www.geotomosoft.com, Malaysia (1996-2018) 
14. P. Strzałkowski, The outline of the protection of mining areas, Publishing House of the Silesian University of Technology, Gliwice (2010) (in Polish)

15. R. Ścigała, Computer aided prediction of rock mass and land surfaces deformations caused by underground mining extraction, Publishing House of the Silesian University of Technology, Gliwice (2008) (in Polish) 